\title{
The role of amino acid metabolism during abiotic stress release
}

\author{
Willian Batista-Silva ${ }^{1,2 *}$ | Björn Heinemann ${ }^{2 *} \mid$ Nils Rugen $^{2}$ | Adriano Nunes-Nesi ${ }^{1}$ | \\ Wagner L. Araújo ${ }^{1}$ (D) । Hans-Peter Braun ${ }^{2}$ (D) | Tatjana M. Hildebrandt ${ }^{2}$ (D)
}

${ }^{1}$ Max-Planck Partner Group at the Departamento de Biologia Vegetal, Universidade Federal de Viçosa, Viçosa, Brazil

${ }^{2}$ Institut für Pflanzengenetik, Leibniz Universität Hannover, Hannover, Germany Correspondence

Tatjana M. Hildebrandt, Institut für Pflanzengenetik, Leibniz Universität Hannover, Herrenhäuser Str. 2, 30419 Hannover, Germany.

Email: hildebrandt@genetik.uni-hannover.de Funding information

National Council for Scientific and Technological Development; Coordenação de Aperfeiçoamento de Pessoal de Nível Superior, Grant/Award Number: PROBRAL \#423/14

\begin{abstract}
Plant responses to abiotic stress include various modifications in amino acid metabolism. By using a hydroponic culture system, we systematically investigate modification in amino acid profiles and the proteome of Arabidopsis thaliana leaves during initial recovery from low water potential or high salinity. Both treatments elicited oxidative stress leading to a biphasic stress response during recovery. Degradation of highly abundant proteins such as subunits of photosystems and ribosomes contributed to an accumulation of free amino acids. Catabolic pathways for several low abundant amino acids were induced indicating their usage as an alternative respiratory substrate to compensate for the decreased photosynthesis. Our results demonstrate that rapid detoxification of potentially detrimental amino acids such as Lys is a priority during the initial stress recovery period. The content of Pro, which acts as a compatible osmolyte during stress, was adjusted by balancing its synthesis and catabolism both of which were induced both during and after stress treatments. The production of amino acid derived secondary metabolites was up-regulated specifically during the recovery period, and our dataset also indicates increased synthesis rates of the precursor amino acids. Overall, our results support a tight relationship between amino acid metabolism and stress responses.
\end{abstract}

\section{KEYWORDS}

Arabidopsis thaliana, drought, hydroponic culture, proteomics, salinity

\section{1 | INTRODUCTION}

Higher plants are sessile and therefore cannot escape adverse environmental conditions that are a constant threat throughout their life cycle. Unfavourable growth conditions such as extreme temperatures (heat, cold, and freezing), drought (deficient precipitation and drying winds), and contamination of soils with high salt concentrations are considered the major abiotic environmental stressors that can not only limit plant growth and development but they also determine the geographic distribution of plant species and directly affect agronomical yield (Krasensky \& Jonak, 2012). Early effects of high salinity and drought on plant metabolism are relatively similar because both restrict the availability of water to plant cells and impose osmotic

*Willian Batista-Silva and Björn Heinemann contributed equally to this study. stress that can lead to turgor loss. To cope with that, plants react with stomatal closure, which inhibits $\mathrm{CO}_{2}$ assimilation and thus triggers a chain of events including accumulation of reducing equivalents, overreduction of plastidial and mitochondrial electron transport chains and as a consequence increased production of reactive oxygen species (ROS) which in turn damage proteins, lipids, and nucleic acids. Prolonged salt stress in addition induces hyperionic stress and secondary deficiencies in $\mathrm{K}^{+}$and $\mathrm{NO}_{3}{ }^{-}$(Chaves, Flexas, \& Pinheiro, 2009; Mahajan \& Tuteja, 2005). Under field conditions, this may even be the predominant factor affecting plant performance (Verslues, Agarwal, Katiyar-Agarwal, Zhu, \& Zhu, 2006).

Plants have evolved different strategies to minimize the adverse effects of abiotic stress conditions and several of them are connected to amino acid metabolism (Hildebrandt, 2018; Madhava Rao, Janardhan Reddy, \& Raghavendra, 2006). For instance, osmotic 
adjustment is achieved by the accumulation of compatible osmolytes that do not interfere with plant metabolism even at high concentrations and may also act as ROS scavengers such as Pro and GABA. Pro synthesis is strongly induced during osmotic stress leading to an accumulation of Pro to high millimolar levels (Verslues \& Sharma, 2010). Thus, increased Pro concentrations can be used as a metabolic stress indicator. Pro content is determined by the balance between synthesis and degradation, and its accumulation capacity has been shown to correlate with abiotic stress tolerance (Szabados \& Savouré, 2010).

Several amino acids can act as precursors for the synthesis of secondary metabolites and signalling molecules. Polyamines are derived from Arg (Alcázar et al., 2006), the plant hormone ethylene is synthesized from Met (Amir, 2010), and immune signalling requires conversion of Lys to N-hydroxy pipecoline (Chen et al., 2018; Hartmann et al., 2018). A broad spectrum of secondary metabolites with multiple biological functions and health promoting properties are further derived from the aromatic amino acids Phe, Tyr, and Trp or from intermediates of their synthesis pathways (Tzin \& Galili, 2010). A general accumulation of free amino acids has usually been observed in different plants exposed to abiotic stress (Aleksza, Horváth, Sándor, \& Szabados, 2017; Barnett \& Naylor, 1966; Draper, 1972; Ferreira Júnior, Gaion, Sousa Júnior, Santos, \& Carvalho, 2018; Fougère, Le Rudulier, \& Streeter, 1991; Huang \& Jander, 2017; Lugan et al., 2010). Extensive amino acid accumulation in response to drought stress has been reported for maize, cotton, tomato, and the resurrection plant (Martinelli et al., 2007; Perez-Alfocea, Estan, Caro, \& Guerrier, 1993; Ranieri, Bernardi, Lanese, \& Soldatini, 1989; Showler, 2002). Recent studies also suggested that autophagy and abscisic acid-induced protein turnover contribute to the increase in free amino acids (Barros et al., 2017; Hildebrandt, 2018; Hirota, Izumi, Wada, Makino, \& Ishida, 2018; Huang \& Jander, 2017). In situations of insufficient carbohydrate supply due to a decrease in photosynthesis rates that usually occur during stress conditions, plants can use amino acids as alternative substrates for mitochondrial respiration (Araújo, Tohge, Ishizaki, Leaver, \& Fernie, 2011; Hildebrandt, 2018; Hildebrandt, Nunes Nesi, Araújo, \& Braun, 2015). The degradation pathways for Lys and the branched-chain amino acids Val, Leu, and Ile have already been identified as essential factors for dehydration tolerance in Arabidopsis (Pires et al., 2016), but the specific role of other catabolic pathways remains unclear. After return to more favourable growth conditions, plants have to reprogram their metabolism and switch back from survival to active growth. Thus, not only metabolic adjustments to the stress conditions but also the efficiency of resuming growth and seed production after stress release will affect plant fitness and consequently crop yield.

By using a hydroponic culture system, here, we investigate the response of amino acid metabolism during the recovery phase following low water potential and salt stress in Arabidopsis thaliana under controlled environmental conditions. Our results provide novel insight into the dynamic behaviour of individual pathways and their potential functions during stress tolerance. They demonstrate that the usage of a relatively simple experimental system is suitable for investigating the mechanisms and regulatory networks associated with efficient recovery from stress.

\section{2 | MATERIALS AND METHODS}

\section{1 | Plant growth conditions and stress treatment}

Seeds of $A$. thaliana Col-0 (10 mg) were sterilized by incubation in $50 \%$ ethanol for $1 \mathrm{~min}$, followed by manual shaking for $2 \mathrm{~min}$. After that, the ethanol was replaced by $6 \%$ of hypochlorite and shaken for another $2 \mathrm{~min}$. Subsequently, the seeds were washed five times by adding $1 \mathrm{ml}$ sterilized water, inverting the tubes for $2 \mathrm{~min}$ and spinning the seeds down. In a final step, $2 \mathrm{ml}$ Agarose $(0.15 \% \mathrm{w} / \mathrm{v}$; SigmaAldrich, Hamburg, Germany) were added to the sterilized seeds. The seed suspension was diluted to a final concentration of $2.5 \mathrm{mg} \mathrm{ml}^{-1}$ of agarose per tube. Plant cultivation took place in specialized glass jars, which include a stainless steel wire mesh platform (125 $\mu \mathrm{m}$ mesh size) that is fixed between two flat rings and held in place by three legs (as developed by Schlesier, Bréton, \& Mock, 2003). One millilitre of the seed/agarose suspension was dispensed on each wire mesh platform. The glass jars were filled to the height of the platform with $\sim 150 \mathrm{ml}$ of a solution including $2.2 \mathrm{~g} \mathrm{~L}^{-1}$ Murashige and Skoog (MS) basal medium (Murashige \& Skoog, 1962; Sigma-Aldrich, Hamburg, Germany) and 0.4\% Agar (Agar Type A, Sigma-Aldrich). Plants were cultivated in a growth chamber at long-day conditions (16 hr light [ $85 \mathrm{\mu mol}$ photon $\mathrm{m}^{-2} \mathrm{~s}^{-1}$ ] and $8 \mathrm{hr}$ dark), a temperature of $23 \pm 2^{\circ} \mathrm{C}$ and a humidity of $60 \pm 5 \%$. For the initial plant cultivation, the abovementioned medium was supplemented with $1 \%(\mathrm{w} / \mathrm{v})$ sucrose. During continued cultivation at stress conditions (see below), supplementation of sucrose was omitted.

Fourteen days after sowing, the wire mesh platforms with seedlings were transferred into new glass jars including liquid medium (150 ml of $2.2 \mathrm{~g} \mathrm{~L}^{-1}$ of MS) supplemented with either (a) $150 \mathrm{mM} \mathrm{NaCl}$ (salt stress), (b) PEG 6000 (water stress; $\Psi_{\mathrm{s}}=-1.0 \mathrm{MPa} ; 290.92 \mathrm{~g} \mathrm{~L}^{-1}$ ), or (c) none of the two compounds (control). The medium supplemented with $\mathrm{NaCl}$ was autoclaved together with the MS medium before use, whereas PEG-6000 was added to the MS medium after autoclaving. Stress treatment was started $1 \mathrm{hr}$ after the beginning of the light period. The seedlings were maintained at the stress conditions for the next $24 \mathrm{hr}$. To investigate the recovery from $\mathrm{NaCl}$ and PEG stress, wire mesh platforms with seedlings were returned to glass jars containing $1 / 2$ MS medium without supplements and cultivated for another $18 \mathrm{hr}$. Leaf material of the plants was harvested at four time points (Figure 1): At the beginning of the stress treatment (immediately before transferring to the new glass jars), at the end of the stress treatment, and after 6 and $18 \mathrm{hr}$ of recovery. Leaves of all plants growing in the same glass jar were pooled. For each time point and condition plant material from four individual glass jars was analysed. Samples were frozen in liquid nitrogen, ground to a fine powder, and stored at $-80^{\circ} \mathrm{C}$ until further use.

\section{2 | Determination of hydrogen peroxide content}

The hydrogen peroxide $\left(\mathrm{H}_{2} \mathrm{O}_{2}\right)$ content of plant extracts was measured after reaction with $\mathrm{KI}$ (potassium iodide) as described by Gharibi, Tabatabaei, Saeidi, and Goli (2016). In brief, extraction was performed using $30 \mathrm{mg}$ of plant material. The powder was resolved in $1 \mathrm{ml}$ of 

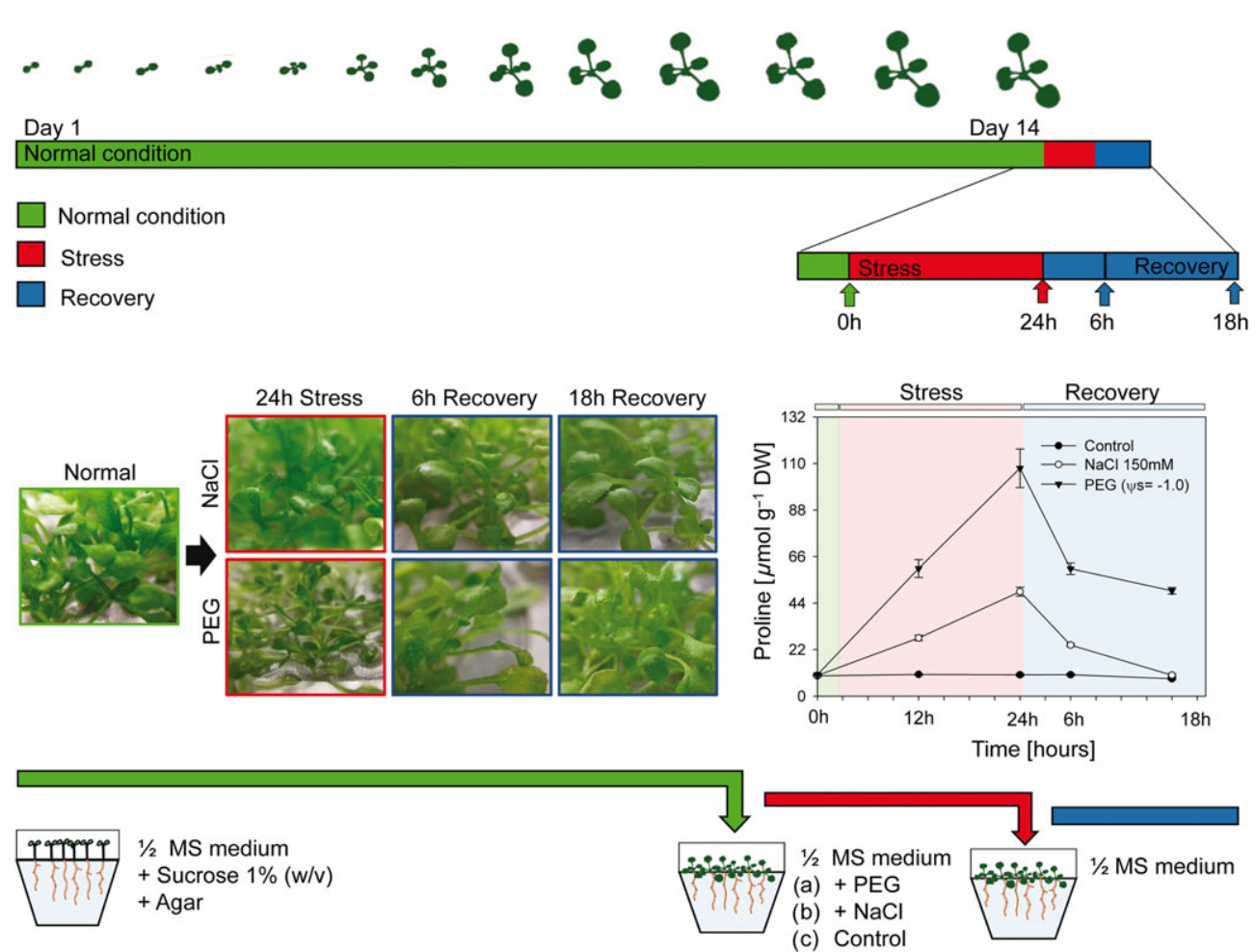

FIGURE 1 Scheme of the experimental set-up for investigating the stress and stress recovery responses in Arabidopsis. Throughout the experiment, plants were cultivated at long-day conditions ( $16 \mathrm{hr}$ light and $8 \mathrm{hr}$ dark; see Section 2 for details). Germination and initial cultivation of plants took place on semi-solid $1 / 2$ MS medium containing $1 \%$ sucrose (green bar). Fourteen days after sowing (DAS), plants were transferred, to liquid $1 / 2 \mathrm{MS}$ medium without sucrose $1 \mathrm{hr}$ after the beginning of the light period and subjected to stress (addition of either $150 \mathrm{mM}$ $\mathrm{NaCl}$ or PEG6000) for $24 \mathrm{hr}$ (red bar). Finally, plants were transferred to liquid $1 / 2 \mathrm{MS}$ medium without additions for stress recovery for $18 \mathrm{hr}$ (blue bar). Plants were harvested and used for all further experiments at the four time points indicated by the colour arrows. Representative pictures of the plants before and after the stress treatments and during the recovery phase are shown. The inserted graph presents leaf proline contents at the time points indicated [Colour figure can be viewed at wileyonlinelibrary.com]

$0.6 \%(\mathrm{w} / \mathrm{v})$ of thiobarbituric acid (Sigma-Aldrich) in $10 \%(\mathrm{w} / \mathrm{v})$ of trichloroacetic acid. Then, the mixture was heated at $100^{\circ} \mathrm{C}$ for $15 \mathrm{~min}$ and centrifuged at $2,400 \mathrm{~g}$ for $10 \mathrm{~min}$. Afterwards, the supernatant $(20 \mu \mathrm{l})$ was combined with $200 \mu \mathrm{l}$ of $100 \mathrm{mM} \mathrm{K}$-phosphate buffer, $\mathrm{pH} 7.0$, and $80 \mu \mathrm{l}$ of $\mathrm{KI} 1 \%(\mathrm{w} / \mathrm{v})$. The blank probe consisted of the same compounds except that the protein extract was omitted. The reaction took place for $1 \mathrm{hr}$ in the dark. Subsequently, absorbance was measured at $390 \mathrm{~nm}$. The amount of $\mathrm{H}_{2} \mathrm{O}_{2}$ was determined according to a standard curve prepared with known concentrations of $\mathrm{H}_{2} \mathrm{O}_{2}$.

\section{3 | Assays of antioxidant enzyme activities}

About $0.25 \mathrm{~g}$ of leaf material was solubilized in $0.5 \mathrm{ml} 50 \mathrm{mM}$ potassium phosphate buffer ( $\mathrm{pH}$ 7.0) containing $1 \mathrm{mM}$ ethylenediaminetetraacetic acid (EDTA), 1\% polyvinylpyrrolidone, and $1 \mathrm{mM}$ ascorbic acid. The homogenate was centrifuged at $15,000 \mathrm{~g}$ for $20 \mathrm{~min}$ at $4^{\circ} \mathrm{C}$, and the supernatant was used for the following enzyme assays. The total protein content was determined as previously described (Bradford, 1976).

Catalase (CAT; EC1.11.1.6) activity was determined as described before with some modifications (Aebi, 1984). In brief, CAT activity was assayed by $\mathrm{H}_{2} \mathrm{O}_{2}$ consumption (extinction coefficient $39.4 \mathrm{mM}$
${ }^{-1} \mathrm{~cm}^{-1}$ ) at $240 \mathrm{~nm}$. The reaction was carried out in a volume of $200 \mu \mathrm{l}(20 \mu \mathrm{l}$ supernatant of the plant extract plus $180 \mu \mathrm{l}$ of a solution containing $50 \mathrm{mM}$ potassium phosphate buffer $(\mathrm{pH} 7.0)$ and $10 \mathrm{mM}$ $\mathrm{H}_{2} \mathrm{O}_{2}$ ). Ascorbate peroxidase (APX; EC1.11.1.11) activity was determined by following the decrease in $A_{290}$ (extinction coefficient $\left.2.8 \mathrm{mM}^{-1} \mathrm{~cm}^{-1}\right)$. The reaction volume was $200 \mu \mathrm{l}(20 \mu$ l supernatant of the plant extract plus $180 \mu \mathrm{l}$ of $50 \mathrm{mM}$ potassium phosphate [pH 7.0], $0.5 \mathrm{mM}$ ascorbic acid, and $0.1 \mathrm{mM}$ of $\mathrm{H}_{2} \mathrm{O}_{2}$ as described in Nakano \& Asada, 1981). Glutathione reductase (GR; EC1.6.4.2) activity was determined by measuring NADPH oxidation at $340 \mathrm{~nm}$ (extinction coefficient $6.2 \mathrm{mM}^{-1} \mathrm{~cm}^{-1}$ ). The assay mixture (volume: $200 \mu \mathrm{l}$ ) included $20 \mu \mathrm{l}$ supernatant of the plant extract plus $180 \mu \mathrm{l}$ of a solution containing $50 \mathrm{mM}$ potassium phosphate buffer ( $\mathrm{pH}$ 7.8), $2 \mathrm{mM}$ of $\mathrm{Na}_{2}$ EDTA, $0.15 \mathrm{mM}$ glutathione disulphide, and $0.15 \mathrm{mM}$ NADPH. The reaction was initiated by adding NADPH as described previously by Schaedle and Bassham (1977). The reaction was monitored for $3 \mathrm{~min}$. Superoxide dismutase (SOD; EC1.15.1.1) was assayed by monitoring the inhibition of the photochemical reduction of nitro blue tetrazolium (NBT) at $560 \mathrm{~nm}(100 \mu \mathrm{mol}$ photons $\mathrm{m}$ ${ }^{-2} s^{-1}$ ) as previously described by Giannopolitis and Ries (1977). The reaction mixture $(300 \mu \mathrm{l})$ contained $20 \mu \mathrm{l}$ of supernatant of the plant extract plus $280 \mu \mathrm{l}$ a solution containing $50 \mathrm{mM}$ of potassium phosphate buffer ( $\mathrm{pH}$ 7.8), $75 \mu \mathrm{M}$ nitroblue tetrazolium, $13 \mathrm{mM}$ methionine, $0.1 \mathrm{mM}$ EDTA, and $2 \mu \mathrm{M}$ riboflavin. 


\section{4 | Determination of metabolite levels}

Photosynthetic pigments were determined according to Porra, Thompson, and Kriedemann (1989). Total proteins were determined as described before (Cross et al., 2006).

\section{5 | Amino acid quantification}

Amino acid profiles were quantified using a modified version of the procedure described by Fürst, Pollack, Graser, Godel, and Stehle (1990). Leaf material was lyophilized using an Alpha 1-2 LD+ freeze dryer (Christ, Osterode, Germany). About $10 \mathrm{mg}$ plant powder was used for the extraction of free amino acids. Samples were solubilized in $800 \mu \mathrm{l}$ of $0.1 \mathrm{M} \mathrm{HCl}$ (Roth, Karlsruhe, Germany). After $15 \mathrm{~min}$ of incubation at room temperature, the samples were centrifuged at $16,100 \mathrm{~g}$ for $5 \mathrm{~min}$. Supernatants were mixed with equal volume of $0.5 \mathrm{M}$ potassium borate buffer ( $\mathrm{pH} 11)$, incubated for $15 \mathrm{~min}$ at room temperature, and centrifuged at $16,100 \mathrm{~g}$ for $5 \mathrm{~min}$. The supernatants were collected and stored at $-20^{\circ} \mathrm{C}$. Shortly before the analysis, $50 \mu \mathrm{l}$ of the extracts were diluted with $300 \mu \mathrm{l} 0.5 \mathrm{M}$ potassium borate buffer $(\mathrm{pH} \mathrm{11)}$ and $280 \mu \mathrm{l} 0.1 \mathrm{M} \mathrm{HCl}$. As internal standard for the derivatization of primary amino acids $5 \mu \mathrm{l}$ of $0.5 \mathrm{mM}$ betaaminobutyrate (Sigma-Aldrich, Hamburg, Germany) was added. For the normalization of the derivatization of the secondary amino acids, $5 \mu \mathrm{l}$ of $0.5 \mathrm{mM}$ sarcosine (Sigma-Aldrich, Hamburg, Germany) was added to the dilution.

During the precolumn derivatization, $7 \mu \mathrm{l}$ of samples were mixed with $18 \mu \mathrm{l} 0.1 \mathrm{M}$ borate buffer (Agilent, Waldbronn, Germany) and $3.5 \mu \mathrm{l}$ ortho-phthaldialdehyde (Agilent, Waldbronn, Germany). After 60 s, $2.8 \mu \mathrm{l}$ 9-fluorenylmethoxycarbonyl chloride (Agilent, Waldbronn, Germany) were added, and subsequently, the derivatization was stopped by adding $90 \mu \mathrm{l}$ of $15 \mathrm{mM}$ acetic acid. Finally, $1 \mu \mathrm{l}$ were injected onto a 100× 2.1 mm Acclaim RSLC 120 C18, $2.2 \mu \mathrm{m}$ (Thermo Fisher, Dreieich, Germany), driven by the Ultra High-Performance Liquid Chromatography (UHPLC) System Ultimate 3000 (Thermo Fisher, Dreieich, Germany) at $40^{\circ} \mathrm{C}$. The gradient was composed of solvent A $(10 \mathrm{mM}$ sodium phosphate and $10 \mathrm{mM}$ sodium tetraborate decahydrate $[\mathrm{pH}$ 8.2]) and solvent $\mathrm{B}$ (methanol:acetonitrile:water [45:45:10]) with a flow rate of $0.71 \mathrm{ml} \mathrm{min}{ }^{-1}$. The gradient programme started with a composition of 98:2 (solvent $A: B$ ), which changed linearly from 0 to $4.4 \mathrm{~min}$ to $71.5: 28.5$, followed by an isocratic step for $0.3 \mathrm{~min}$. From 4.7 to $6.9 \mathrm{~min}$, solvent A reduced further to $43 \%$, followed again by an isocratic step till $9 \mathrm{~min}$. At $9.8 \mathrm{~min}$, the composition reached 0:100 (A:B) and remained for $5.7 \mathrm{~min}$, to wash the column. At $15.7 \mathrm{~min}$, the initial composition of 98:2 (A:B) was used for $4.3 \mathrm{~min}$ to re-equilibrate the column for the next run. Amino acids were detected using a Fluorescence detector 3400 RS and UVDetector 3100 (Thermo Fisher, Dreieich, Germany). Primary amino acids were excited with $337 \mathrm{~nm}$ wavelength, whereas the emitted light at $442 \mathrm{~nm}$ was measured. Secondary amino acids were excited with $266 \mathrm{~nm}$, and the emitted signals detected at $305 \mathrm{~nm}$. Standards were prepared using the amino acid standard solution from SigmaAldrich (AAS18-5ML), stacked with L-Asparagine, L-Glutamine, gamma-Aminobutyrate, beta-Aminobutyrate, L-Tryptophan and
Sarcosine (each from Sigma-Aldrich, Hamburg, Germany). Evaluation of the peak areas was done with the software Chromeleon 7.2 SR4 (Thermo Fisher, Dreieich, Germany).

\section{6 | Proline quantification}

The proline content was measured as previously described by Abrahám, Hourton-Cabassa, Erdei, and Szabados (2010), with modifications. A total of $10 \mathrm{mg}$ lyophilized plant powder was used for proline extraction as described above for amino acid extraction. The sample extract was prepared in a reaction mixture containing $100 \mu \mathrm{l}$ of sulfosalicylic acid (3\%, w/v), $200 \mu \mathrm{l}$ of acidic ninhydrin, (1.25 g ninhydrin (1,2,3-indantrione monohydrate), $30 \mathrm{ml}$ glacial acetic acid, $20 \mathrm{ml}$ of $6 \mathrm{M}$ orthophosphoric acid), $200 \mu \mathrm{l}$ of glacial acetic acid. To start the reaction, $100 \mu \mathrm{l}$ of sample extract was added to the reaction mixture, incubated at $96^{\circ} \mathrm{C}$ for $60 \mathrm{~min}$ in the dark. Transfer on ice stopped the reaction. After that, $1 \mathrm{ml}$ of toluene (Sigma-Aldrich) was added, vortexed and kept at room temperature for $5 \mathrm{~min}$ to allow the separation of the organic and the water phase. A total of $200 \mu$ l of the chromophore phase $(200 \mu \mathrm{l})$ containing the toluene was transferred into a fresh quartz 96 -well plate and read by a microplate reader at $520 \mathrm{~nm}$. The system was calibrated by measuring known proline concentrations.

\section{7 | Label-free quantitative shotgun mass spectrometry}

Protein extraction and sample preparation for label-free quantitative shotgun mass spectrometry analysis were performed as described by Thal, Braun, and Eubel (2018). Tandem mass spectrometry (MS/MS) analysis was performed using a Q-Exactive mass spectrometer coupled to an Ultimate 3000 UPLC (Thermo Fisher Scientific, Dreieich, Germany) as described in Fromm, Göing, Lorenz, Peterhänsel, and Braun (2016).

For MS data interpretation, the software MaxQuant (Version 1.5.5.1) was used, including the Andromeda search engine (Cox \& Mann, 2008) against the TAIR 10 database. Max Quant and Andromeda settings were selected as described in Thal et al. (2018). The final analysis and comparison of the protein identification lists were done with Perseus (Version 1.5.5.3; Tyanova et al., 2016). In brief, MaxQuant LFQ (Label Free Quantification) values were imported and proteins only identified by a single peptide containing a modification, decoy entries, as well as common contaminations were removed. The data were transformed to $\log _{2}$ and grouped (40 samples: four biological replicates for $0 \mathrm{hr}$ stress, $24 \mathrm{hr}$ stress (PEG, $\mathrm{NaCl}$, control), $6 \mathrm{hr}$ recovery (PEG, $\mathrm{NaCl}$, control), and $18 \mathrm{hr}$ recovery (PEG, $\mathrm{NaCl}$, control), respectively). Protein entries were classified as "valid" if they were identified in at least three replicates of at least one group.

Proteins were assigned to functional categories according to the MapMan annotation file (version Ath_AGI_LOCUS_TAIR10_ Aug2012). Enrichment of specific categories within the proteins with significantly changed abundance in the individual treatments compared with the control was calculated as the relative abundance of 
the category in the analysed group divided by the relative abundance in the complete proteomics dataset.

\subsection{Root toxicity test}

The toxicity of certain amino acids to $A$. thaliana was tested in vitro by analysing the root growth in the presence of the respective amino acid. The experiment was performed in a growth chamber at $22^{\circ} \mathrm{C}$, $85 \mu \mathrm{mol} \mathrm{s}{ }^{-1} \mathrm{~m}^{-2}$ light, $16 \mathrm{hr}$ light, and $8 \mathrm{hr}$ darkness. For the initial rooting, seeds were sterilized and placed on $1 / 2$ MS Medium with $1 \%$ sucrose and $1 \%$ agar for 3 days. Ten similarly developed seedlings were then transferred to squared agar plates supplemented with $100 \mu \mathrm{M}$ of the respective amino acid. Plates were placed upstanding to let the roots grow vertically along the medium. After 8 days, the roots were measured with the AxioVison software (Carl-Zeiss, Jena).

\section{9 | Statistical analysis}

The experiment was performed in a completely randomized design, with four replicates per treatment. Additionally, the complete set-up was repeated at least four times with similar phenotypes observed each time. Statistical analysis of the MS dataset was performed in Perseus using two-sample $t$ tests $(P<0.05)$. For amino acid profiles, the averages of the treatments were compared by the Tukey's test $(P<0.05)$ using the GENES software (Cruz, 2013). Statistical analysis of root lengths was performed using the Mann-Whitney $U$ test.

\section{3 | RESULTS}

\subsection{Investigation of stress and stress release in a hydroponic culture system}

We adapted a hydroponic culture system previously developed (Schlesier et al., 2003) to investigate changes in amino acid metabolism in Arabidopsis during osmotic stress as well as in the early recovery period. Plants were cultivated under controlled environmental conditions in sealed glass jars (Figure 1). Seeds were placed on platforms covered with steel mesh allowing to quickly modify the conditions in the growth medium by transferring the platform to a new glass jar. Preliminary experiments were conducted to establish the optimal experimental conditions including (a) the time point for the beginning of the stress treatment, (b) the intensity and duration of the stress period, and (c) the duration of the recovery phase. Leaf Pro content was monitored as a marker for osmotic stress response. We selected plants that were severely stressed but still able to recover completely. The final set-up included cultivating plants under control conditions for 2 weeks, followed by the exposition to stress treatments (150 mM NaCl; $291 \mathrm{~g} \mathrm{~L}^{-1}$ PEG; control without stress) for $24 \mathrm{hr}$ and afterwards return to control conditions (Figure 1; see Section 2 for details). Shoots were harvested before and at the end of the stress treatment as well as after 6 and $18 \mathrm{hr}$ of recovery.

The plants were apparently severely stressed after $24 \mathrm{hr}$ of PEG or $\mathrm{NaCl}$ treatment as reflected by shrivelled leaves and in case of PEG even a brownish colour (Figure 1). They recovered almost completely within the first $6 \mathrm{hr}$ of stress release with only individual leaves still showing necrotic lesions. In order to assess the general condition of the plants, we analysed oxidative stress parameters as well as the chlorophyll, amino acid, and protein content (Figure 2). Principal component analysis illustrates the significant impact of the stress treatment on these variables and the gradual return to control levels during recovery (Figure S1). Both hydrogen peroxide content and the activities of enzymes involved in the antioxidative system were consistently increased after the stress period, an effect that was stronger for PEG than for $\mathrm{NaCl}$ treatment (Figures 2 and S2). Catalase, glutathione reductase, and superoxide dismutase activity returned to control levels after $6 \mathrm{hr}$ of stress release in the $\mathrm{NaCl}$ treated samples indicating a quick recovery from oxidative stress. The decrease in antioxidative enzyme activities was slower after PEG treatment, and ascorbate peroxidase activity remained at higher levels throughout the recovery phase. PEG stress led to a decrease in leaf chlorophyll and protein content, which were completely (protein) or partially (chlorophyll) restored within $18 \mathrm{hr}$ of release. By contrast, the protein but not the chlorophyll content was affected by salt stress.

\subsection{Global responses of the Arabidopsis leaf proteome during stress and stress release}

Total leaf protein fractions were isolated from plants harvested before and after the stress treatment and after 6 and $18 \mathrm{hr}$ of recovery and subjected to label-free shotgun proteomics. A total of 1,839 proteins were detected in at least three replicates of one group and on that basis selected for further analysis (Table S1). In order to obtain a general overview regarding the proteomic stress response, we grouped all proteins into functional categories according to MapMan (Thimm et al., 2004). This dataset was used for enrichment analysis to identify the most relevant pathways during stress and/or recovery (Figure 3), and in addition, protein abundance profiles were calculated for all functional categories (Figure 4). A total of 707 proteins were significantly changed after PEG stress and a large fraction of them remained increased or decreased also during the recovery phase (Figure 3a, dark grey bars; Figure 3b, top box). In comparison, high salinity led to rather short-term proteome modifications. Aminotransferases as well as heat shock proteins were consistently increased during stress and recovery in both, $\mathrm{PEG}$ and $\mathrm{NaCl}$ stress, whereas ribosomal and photosystems proteins were of lower abundance indicating increased turnover of such highly abundant proteins. Enrichment analysis as well as the heatmaps also demonstrated that other categories related to photosynthesis including light reactions, Calvin-Benson cycle, photorespiration, and tetrapyrrole synthesis were strongly down-regulated following the stress treatment. As a potential compensation, PEG treatment led to an induction of pathways involved in heterotrophic energy metabolism such as the degradation of lipids, proteins and cell walls, glycolysis, and the tricarboxylic acid (TCA) cycle. There was a biphasic oxidative stress response in PEG treated plants with an initial peak in catalase and glutathione-S-transferase abundance during the stress period followed by a gradual increase in peroxidase abundance during the recovery phase. 


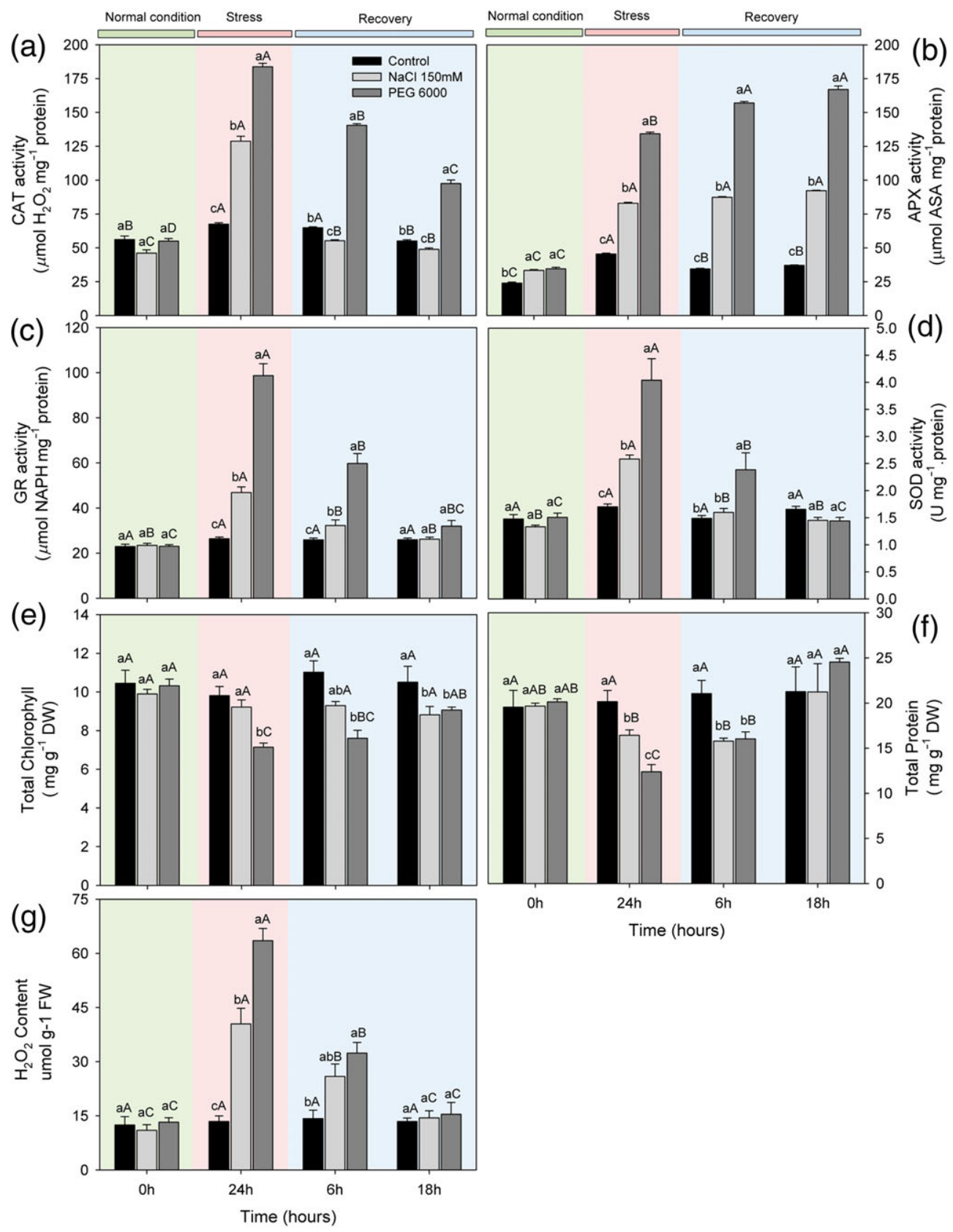

FIGURE 2 Physiological and biochemical properties of Arabidopsis plants during stress and stress recovery. Plants were characterized before stress ( $0 \mathrm{hr}$; indicated by green colour), at the end of the stress period ( $24 \mathrm{hr}$; red), and during stress recovery (6 and $18 \mathrm{hr}$; blue). Activities of selected enzymes involved in the antioxidative system. (a) CAT: catalase. (b) APX: ascorbate peroxidase. (c) GR: glutathione reductase. (d) SOD: superoxide dismutase. Additionally, were measured (e) total chlorophyll, (f) total protein, and the (g) contents of $\mathrm{H}_{2} \mathrm{O}_{2}$ with respect to fresh weight $(F W)$ or dry weight (DW) as indicated. Data presented are means $\pm S E(n=4)$. Different letters represent average values that were judged to be statistically different between samples $(P<0.05$, Tukey test). Small letters refer to the comparison between treatments at the same time points and capital letter to comparisons between individual treatments over time [Colour figure can be viewed at wileyonlinelibrary.com]

\subsection{Amino acid metabolism during stress and stress release}

Enrichment analysis also revealed a prominent role of amino acid metabolism during stress and stress release (Figure $3 b$ ). In addition to the sustained induction of aminotransferases, the synthesis pathways for Arg and aromatic amino acids were significantly up-regulated on a protein level specifically during the recovery phase following both PEG and salt stress. In contrast, the abundance of branched-chain amino acid biosynthetic enzymes was significantly decreased after the stress. In order to understand the interactions of amino acid metabolism and stress response in more detail, we additionally measured leaf amino acid profiles (Tables S2 and S3) and integrated all the information in a comprehensive metabolic pathway map (Figure 5). This map represents all currently known enzymatic steps involved in plant amino acid synthesis (arrows pointing at the amino acids) and amino acid degradation (arrows pointing away from the amino acids; Hildebrandt, 2018). In addition, committed steps leading to the synthesis of secondary metabolites are also shown (in italics). 
(a)

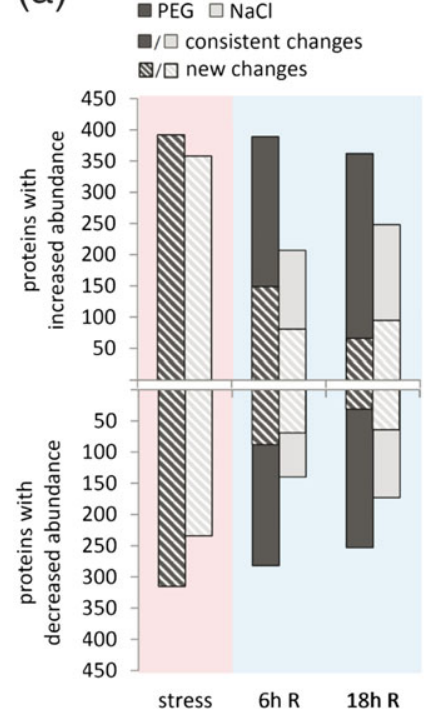

(b)

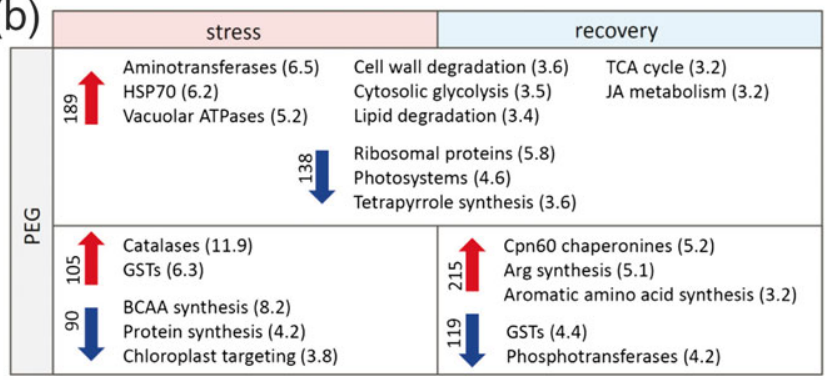

\begin{tabular}{|c|c|c|c|}
\hline \multirow{2}{*}{$\begin{array}{l}\overline{\widetilde{T}} \\
\bar{Z}\end{array}$} & \multicolumn{3}{|c|}{ 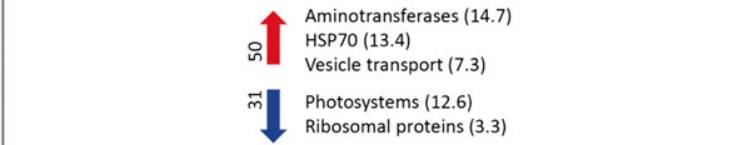 } \\
\hline & जी & $\begin{array}{l}\text { Porins (11.7) } \\
\text { Proteasome (4.4) } \\
\text { Vacuolar ATPases (3.9) } \\
\text { Tetrapyrrole synthesis (7.8) } \\
\text { Lys (7.8) and BCAA (3.1) synthesis } \\
\text { Photorespiation (6.5) } \\
\text { Calvin cycle (5.0), RNA binding (4.9) }\end{array}$ & $\begin{array}{ll} & \text { Arg synthesis (6.3) } \\
\text { Cpn60 chaperonines (4.4) } & \text { Thioredoxin (4.1) } \\
\text { Aromatic amino acid synthesis (3.5) } \\
\\
\text { M. Met synthesis (4.6) } \\
\text { Ribosomal proteins (4.2) }\end{array}$ \\
\hline
\end{tabular}

FIGURE 3 Significant changes in the Arabidopsis leaf proteome during stress and recovery period. Total protein fractions were isolated from plants harvested at the time points indicated in Figure 1 and subjected to label-free shotgun proteomics (see Section 2 for details). Log ${ }_{2}$-fold changes in protein abundances were calculated for the stress treated versus control plants, and significant changes in abundance were identified by Student $t$ test $(P<0.05)$. (a) Number of proteins with significantly increased or decreased abundance in stress treated versus control plants after the stress treatment (stress), after $6 \mathrm{hr}$ of recovery ( $6 \mathrm{hr} \mathrm{R}$ ), and after $18 \mathrm{hr}$ of recovery (18 hr R). Proteins with consistently changed abundance during the stress and recovery phase are represented by filled bars, whereas significant changes that were not present in the previous time points are shown as striped areas. (b) Enrichment analysis to identify functional protein categories that are consistently regulated during the stress and recovery period (shown in the upper part of the boxes) or specific for either stress or stress release (shown at the bottom). Numbers next to the arrows indicate the total number of significantly increased (red arrows) or decreased (blue arrows) proteins. The enrichment factors are given in parentheses after the names of the categories. The full shotgun proteome dataset is given in Table S1 [Colour figure can be viewed at wileyonlinelibrary.com]

Pro accumulation during the stress treatment followed by a decrease in the recovery phase had been used as a marker for osmotic stress response for establishing the experimental set-up, and our dataset further confirms that the synthesis pathway for Pro was induced during salt as well as PEG stress (Figure $5 \mathrm{~d}$; Table S4). This response was stronger and more persistent with PEG than with $\mathrm{NaCl}$. Interestingly, the abundance of delta-1-pyrroline-5-carboxylate dehydrogenase, an enzyme involved in Pro degradation, was already induced during the stress treatment and remained on a high level during stress release (Figure 5d; Table S4). Overall, the effect of salt stress on the leaf amino acid profile was less pronounced than for PEG treatment. Only four of the 20 amino acids analysed significantly changed their contents after salt stress, and three additional ones changed only during the recovery phase (Table S3). In contrast, four amino acids remained completely unaffected by PEG stress, whereas 10 were increased throughout the entire experiment. The total free amino acid content, calculated as the sum of all amino acids in our profile, increased during stress and showed a second peak during late recovery (Table S3). Gly was the only amino acid with a consistently lower content in stressed plants compared with controls. Gln and Ala strongly accumulated during the recovery period from PEG treatment. After salt stress, there was an initial reduction in the contents of Gln, Arg, and Asn after $6 \mathrm{hr}$ of recovery before they returned to control levels after $18 \mathrm{hr}$. Arg decreased significantly during recovery from PEG, which might be explained by a high demand for precursors of polyamine synthesis, because this pathway was induced (Figure $5 \mathrm{~d}$ ). Amino acid derived secondary metabolism was generally up-regulated during stress and recovery with the exception of ethylene production from Met. This finding is in good agreement with the observed induction of aromatic amino acid synthesis because these are precursors for a diverse set of secondary metabolites such as glucosinolates, alkaloids, and phenylpropanoids.

Concentrations of the low abundant amino acids (branched-chain amino acids, Lys, Met, His, and aromatic amino acids) showed the strongest relative increase after PEG treatment, whereas there was no significant change compared with the control after $\mathrm{NaCl}$ stress. The synthesis pathways of these amino acids were generally downregulated during both stress conditions investigated and gradually returned to control levels during recovery. In contrast, the degradation pathways were strongly induced and in several cases peaked during early recovery before decreasing again (Figure 5a-c; Table S4). Looking at the absolute amino acid concentrations in the leaves, it becomes obvious that some of the low abundant amino acids such as Lys and Leu accumulated during PEG stress but were degraded very fast after stress release, whereas others (Val, Ile, His) remained elevated (Figure 6a). Proteomics show that LKR/SDH and aldehyde dehydrogenase 7B4 catalysing the first steps in Lys degradation were strongly induced during PEG treatment and remained on a high level also throughout the recovery phase (Figure 6b). Induction of enzymes involved in branched-chain amino acid catabolism seemed to be less pronounced and of a more transient nature.

To test whether toxic effects could be the reason for preferential degradation of specific amino acids, we further performed a root growth inhibition assay (Figure $6 c$ ). Indeed, Lys turned out to be the 


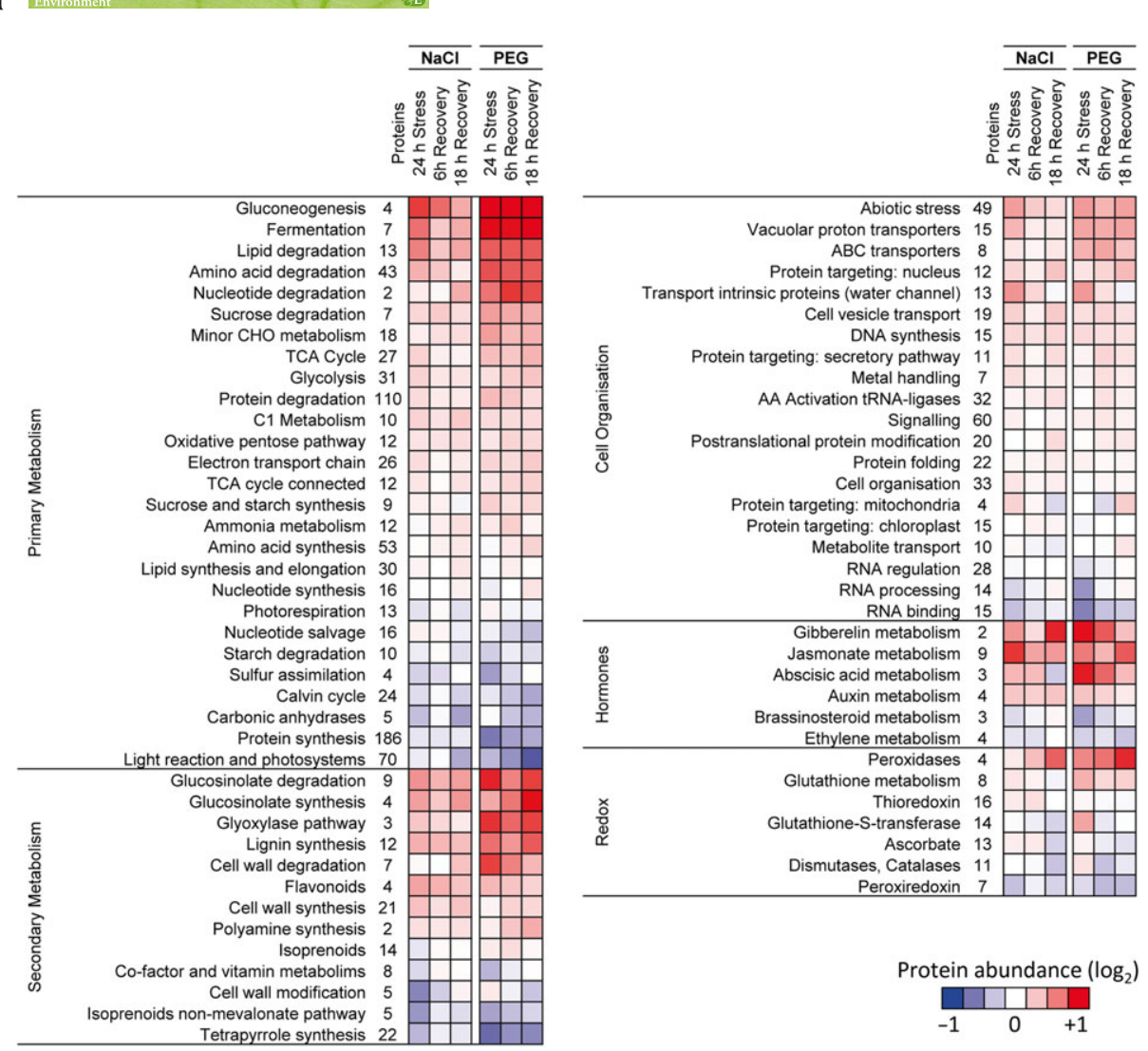

FIGURE 4 Heatmap representing protein abundance profiles during stress and recovery period. Total protein fractions were isolated from plants harvested at the time points indicated in Figure 1 and subjected to label-free shotgun proteomics (see Section 2 for details). Log ${ }_{2}$-fold changes in protein abundances were calculated for the stress treated versus control plants. The colour gradient represents the means of all log ${ }_{2}$-ratios (scaling: -1 to +1 ) for proteins included in the functional categories listed according to the MapMan annotation file (version Ath_AGI_LOCUS_TAIR10_Aug2012). Red colours: increased abundance with respect to the reference fraction. Blue colours: decreased abundance with respect to the reference fraction. The full shotgun proteome dataset is given in Table S1 [Colour figure can be viewed at wileyonlinelibrary. com]

most toxic amino acid and inhibited the growth of Arabidopsis roots by $80 \%$ at a concentration of $100 \mu \mathrm{M}$ followed by Leu (62\% inhibition) and Met (44\% inhibition). By sharp contrast, Val and lle showed only mild toxic effects, whereas His addition even slightly promoted root growth.

\section{4 | DISCUSSION}

Our approach aimed at specifically addressing the behaviour of amino acid metabolism during the recovery phase from high salinity and low water potential in the model plant $A$. thaliana. Our in vitro experimental system provided reliable and reproducible conditions during stress and more importantly in the recovery period. In contrast to soil-based techniques, it allows rapid and accurate modification of the water potential and the salt concentration in the medium. The advantages of PEG as a drought stress inducer have been repeatedly demonstrated (Frolov et al., 2017; van der Weele, Spollen, Sharp, \& Baskin 2000; Verslues et al., 2006). Although caution must be taken when analysing such results due to potential effects of the artificial growth conditions such as crowding, hypoxia, or the supply of sucrose in the initial growth medium, our experimental system had very little effect on amino acid metabolism in control plants. Therefore, we conclude that our approach is highly suitable for investigating the effect of stress and stress release on amino acid metabolism in order to complement the results obtained with soil-based systems.

\section{1 | Stress recovery: Re-establishing photosynthesis and fighting ROS}

Photosynthesis is one of the primary processes affected by drought and salt stress (Chaves, 1991; Munns, James, \& Läuchli, 2006). The decreased availability of $\mathrm{CO}_{2}$ due to diffusion limitations directly restrict photosynthesis rates but also leads to secondary effects such as photo-oxidative damage and increased protein turnover (Chaves et al., 2009). The carbon balance of a recovering plant may thus depend on both the degree of damage induced during stress as well as the velocity and extent of photosynthetic recovery. Our results confirm a sharp increase in oxidative stress after PEG as well as $\mathrm{NaCl}$ treatment leading to an induction of protective enzymes such as chaperones, catalase, and glutathione S-transferase. Although plants were able to eliminate ROS levels within $18 \mathrm{hr}$ of recovery, the chlorophyll content as well as the abundance of proteins from the photosystems still remained low, indicating an incomplete recovery of the photosynthetic activity. In addition, ribosomal proteins were clearly enriched in the group of proteins with consistently reduced abundance after stress treatments as well as during the recovery period. Preferential 


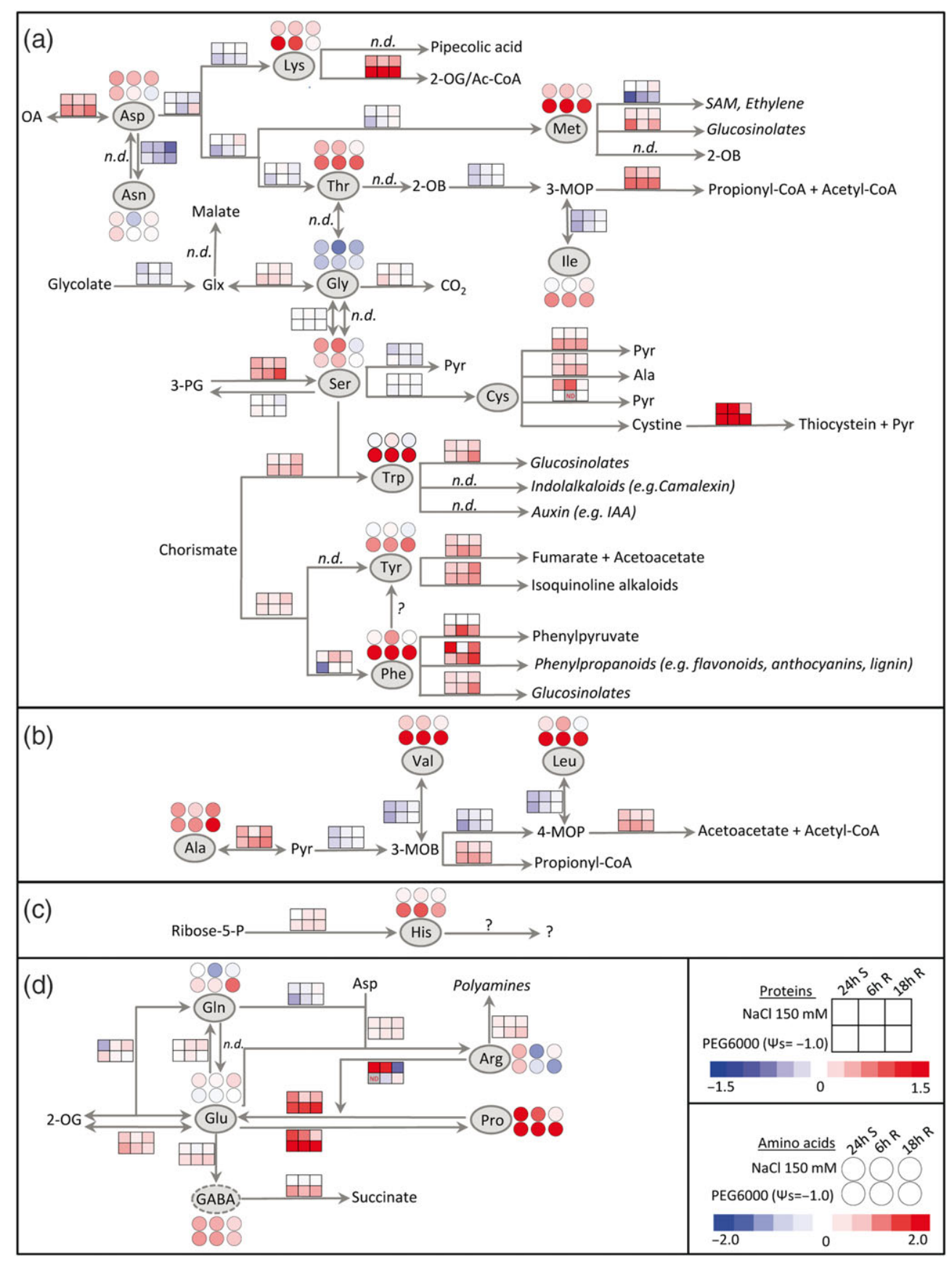

FIGURE 5 Amino acid metabolism during stress and stress release. Log $_{2}$-fold changes in amino acid contents (heatmap circles) and abundances of enzymes involved in amino acid metabolism (heatmap squares). Red colours: increased with respect to the control fraction. Blue colours: decreased with respect to the control fraction. All values are means from four biological replicates. The complete amino acid profile including statistical analysis can be found in Table S3. Log $_{2}$-fold changes in the abundance of currently known enzymes involved in amino acid synthesis and degradation pathways as well as of the enzymes catalysing committed steps leading to the synthesis of amino acid derived secondary metabolites were extracted from the proteomics dataset (Table S1). The coloured squares represent the means of all changes in the abundance of enzymes involved in the respective branch of the pathway. Arrows leading to amino acids represent the synthesis pathways, arrows pointing away from the amino acid show catabolic reactions, and metabolites that can be interconverted by a single set of enzymes are connected by arrows pointing in both directions. Pathways and metabolites marked by a question mark are presently unknown. The complete enzyme list including the proteomics results as well as the position of each enzyme within the pathway scheme is shown in Table S4 and Figure S3. 2-OB: 2-oxobutyrate; 2-OG: 2oxoglutarate; 3-MOB: 3-methyl-2-oxobutanoate; 3-MOP: 3-methyl-2-oxopentanoate; 3-PG: 3-phosphoglycerate; 4-MOP: 4-methyl-2oxopentanoate; GABA: $\gamma$-aminobutyric acid; Glx: glyoxylate; IAA: indole-3-acetic acid; n.d.: not detected; OA: oxaloacetic acid; Pyr: pyruvate; SAM: S-adenosyl methionine [Colour figure can be viewed at wileyonlinelibrary.com]

degradation of the photosystems proteins might be associated with a high frequency of photo-oxidative damage. Ribosomal proteins are highly abundant and thus sequester a large amount of the cell's resources. In addition, protein synthesis consumes a considerable fraction of the cells' ATP and precursor supply. Consequently, cells react to various stresses by translation arrest to release energy and resources for stress responses (Cebollero, Reggiori, \& Kraft, 2012). Selective degradation of ribosomes (ribophagy) under nutrient 
(a) Amino acid content

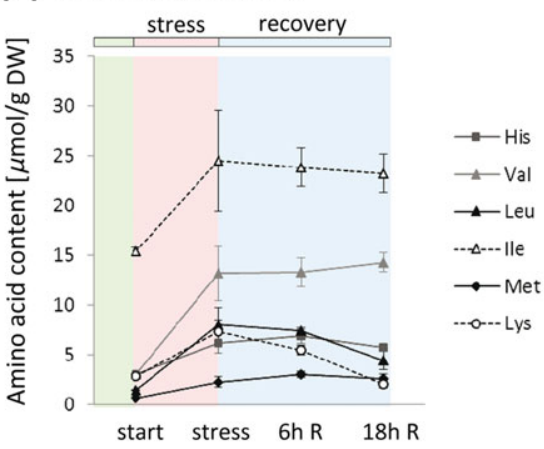

(b) Amino acid catabolism

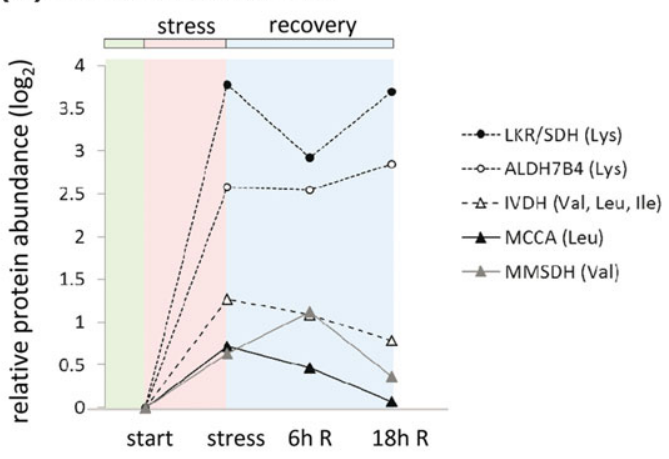

(c) Toxic effect of amino acids on root growth
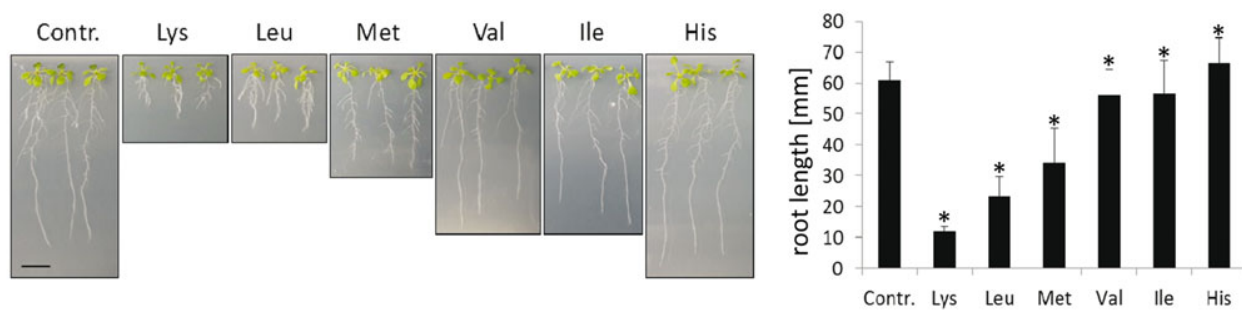

FIGURE 6 Rapid degradation of toxic amino acids during PEG stress and stress release. (a) Leaf contents ( $\mu \mathrm{mol}^{\mathrm{g}} \mathrm{DW}^{-1}$ ) of low abundant amino acids during PEG stress and recovery. Please note that lines have been added for eye guidance only. (b) Relative abundance (log 2 treatment/ control) of enzymes involved in the degradation of low abundant amino acids during stress and recovery. LKR/SDH: lysine-ketoglutarate reductase/saccharopine dehydrogenase bifunctional enzyme (AT4G33150, Lys catabolism); ALDH7B4: aldehyde dehydrogenase 7B4 (AT1G54100, Lys catabolism); IVDH: isovalery-CoA carboxylase alpha chain (AT3G45300, BCAA degradation); MCCC: methylcrotonyl-CoA carboxylase alpha chain (AT1G03090, Leucine degradation); MMSD4: methylmalonate semialdehyde dehydrogenase (AT2G14170, valine degradation). Lines are for eye guidance only. (c) Root toxicity test: Arabidopsis plants were grown on vertical agar plates containing no amino acid (control) or $100 \mu \mathrm{M}$ Lys, Leu, Met, Val, Ile, or His. Scale bar: $1 \mathrm{~cm}$. Mean root lengths were calculated from 40 plants per treatment (see Tables S1S3 for primary data) [Colour figure can be viewed at wileyonlinelibrary.com]

starvation conditions has been first described in yeast cells (Kraft, Deplazes, Sohrmann, \& Peter, 2008) and a similar process has also been proposed for plants (Floyd, Morriss, Macintosh, \& Bassham, 2012). Our results indicate that ribosomes are degraded within the first $24 \mathrm{hr}$ of salt stress or low water potential, and control levels are not restored within $18 \mathrm{hr}$ of recovery. As a consequence, protein synthesis might still be limited for a considerable period after the stress has been alleviated potentially affecting the replacement of damaged photosystems and slowing down the complete recovery process.

\section{2 | Stress recovery: The significance of amino acid metabolism}

In general, the content of free amino acids in plants increases considerably during different abiotic stress conditions. The reason for this accumulation might be different for individual amino acids. Synthesis rates of the amino acid can be up-regulated, degradation downregulated, and in addition, it can be produced by proteolysis or consumption can be restricted due to a decrease in protein synthesis or secondary metabolite production. Our study provides insight into the direction of metabolism for different proteinogenic amino acids during stress and stress release and their potential function in stress tolerance. The main results are summarized in Figure 7 and are discussed below.

\subsection{1 | Pro homeostasis as a balance between syn- thesis and degradation}

The role of Pro as a compatible osmolyte during abiotic stress conditions associated with low water availability has been extensively demonstrated (Liang, Zhang, Natarajan, \& Becker, 2013; Szabados \& Savouré, 2010). We also observed a strong induction of Pro synthesis after $\mathrm{NaCl}$ as well as PEG treatment. Mitochondrial Pro catabolism contributes to ATP production by directly transfering electrons into the respiratory chain and also produces Glu that can be converted into the TCA cycle intermediate 2-oxoglutarate by glutamate dehydrogenase (Schertl \& Braun, 2014). This pathway is seemingly relevant for increased drought resistance and can act as a buffer of the cellular redox status (Bhaskara, Yang, \& Verslues, 2015; Shinde, Villamor, Lin, Sharma, \& Verslues, 2016). Delta-1-pyrroline-5-carboxylate dehydrogenase $(\mathrm{P} 5 \mathrm{CDH})$ is induced by high Pro concentrations most likely to prevent accumulation of the toxic degradation intermediate $\Delta^{1}$ pyrroline-5-carboxylate, which might serve as a signalling molecule promoting programmed cell death (Deuschle et al., 2001; Deuschle et al., 2004). The regulation of proline dehydrogenase (ProDH), the initial enzyme of the Pro degradation pathway, seems to be more complex. Expression of the main isoform ProDH1 is strongly induced by Pro, but high salinity or PEG treatment can prevent this induction (Peng, Lu, \& Verma, 1996; Sharma \& Verslues, 2010). Our proteomics dataset does not include ProDH but demonstrates that $\mathrm{P} 5 \mathrm{CDH}$ is already up-regulated on a protein level during stress, which in the 


\begin{tabular}{|c|c|c|c|c|c|}
\hline \multirow{2}{*}{ Amino acid } & \multicolumn{2}{|c|}{ Direction of metabolism } & \multicolumn{2}{|c|}{ Amino acid profile } & \multirow{2}{*}{ Role in stress response } \\
\hline & Stress & Recovery & PEG & $\mathrm{NaCl}$ & \\
\hline Pro & $\begin{array}{l}\text { Synthesis + } \\
\text { Degradation }\end{array}$ & $\begin{array}{l}\text { Synthesis + } \\
\text { Degradation }\end{array}$ & & & compatible osmolyte \\
\hline $\begin{array}{l}\text { Ala } \\
\text { Gln }\end{array}$ & Synthesis & Synthesis & & & nitrogen store \\
\hline $\begin{array}{c}\text { Trp,Phe,Tyr } \\
\text { Ser } \\
\text { Arg }\end{array}$ & $\begin{array}{c}\text { Synthesis } \\
\text { (+ Degradation*) }\end{array}$ & $\begin{array}{l}\text { Synthesis } \\
\text { (+ Degradation* }\end{array}$ & & & $\begin{array}{c}\text { precursor for } \\
\text { secondary } \\
\text { metabolites }\end{array}$ \\
\hline $\begin{array}{l}\text { Leu, Val, Ile, } \\
\text { Lys (Thr, Met) }\end{array}$ & Degradation & Degradation & & & $\begin{array}{l}\text { ATP production, } \\
\text { detoxification }\end{array}$ \\
\hline
\end{tabular}

FIGURE 7 Schematic summary of amino acid metabolism during osmotic stress and stress release. The dominant direction of amino acid metabolism during stress and recovery, which was similar for PEG and $\mathrm{NaCl}$, is indicated in the red and blue fields. Mean relative protein abundances (treatment vs. control) of all enzymes involved in the synthesis and degradation pathways, respectively, were calculated for each individual amino acid in order to estimate up- or down-regulation of the pathway. Pathways that were on average induced are listed in the figure. Thr and Met are shown in parentheses because catabolic enzymes were not detected in our proteomics dataset and thus increased catabolism can only be postulated on the basis of amino acid contents and down-regulation of the synthesis pathways. The symbol "*” indicates only some of the degradation pathways were induced. The amino acid profiles are summarized by line plots. Red lines indicate the development of amino acid contents during stress treatment and blue lines represent the recovery phase [Colour figure can be viewed at wileyonlinelibrary.com]

presence of sufficient amounts of ProDH could lead to simultanuous synthesis and degradation of Pro and thus waste valuable resources. However, a regulatory protein (DFR1) has been recently identified as able to inhibit mitochondrial Pro degradation during drought stress and freezing by directly interacting with the two catabolic enzymes ProDH and delta-1-pyrroline-5-carboxylate dehydrogenase (Ren et al., 2018). Thus, one possible scenario would be that plants already prepare themselves during stress for rapid removal of Pro in the recovery phase by increasing the amount of catabolic enzymes and at the same time prevent a futile cycle via post-translational regulation.

\subsubsection{Amino acid synthesis for nitrogen storage and secondary metabolite production}

The biosynthetic pathways of certain additional amino acids, namely, aromatic amino acids, Ser, Arg, Gln, and Ala were also up-regulated during PEG as well as salt stress and stress release (Figure 7). The content of free Ala and GIn continuously increased in particular during recovery from PEG stress indicating that these amino acids might be used for storage of the amino groups liberated during degradation of other amino acids. This is in line with the consistent induction of aminotransferases, most of which use either Pyr or 2-oxoglutarate as a substrate to produce Ala and Glu. Thus, accumulation of specific amino acids might be associated with storage of precursors for protein synthesis to prepare for rapid recovery of plant metabolism following stress. It seems reasonable to suggest that this situation also occurs in response to less severe stress conditions experienced by most plants at some stage during their life cycle. Interestingly, we observed a transient decrease in the content of nitrogen storage amino acids during early recovery from salt stress and also a reduction in total free amino acids for both stress conditions analysed. These findings indicate a high demand for nitrogen during initial stress release potentially for increased production of non-protein amino acids or other nitrogen containing metabolites that are not detected in our HPLC approach.

Secondary metabolites of the phenylpropanoid group are synthesized through the shikimate pathway by phenylalanine ammonia lyase (PAL), which is induced by several adverse environmental conditions (Tzin \& Galili, 2010). We detected increased amounts of PAL 1 during salt stress and stress release. There was also a consistent induction of trans-cinnamate 4-monooxygenase involved in phenlypropanoid synthesis and tyrosine aminotransferase required for the conversion of Tyr to isoquinoline alkaloids during stress as well as in the following recovery period for both stress conditions used here. Leaf contents of the aromatic amino acids were significantly increased (two to fivefold) after PEG treatment and remained on a high level throughout the recovery period (18 hr). The enzymes involved in aromatic amino acid synthesis were generally induced indicating that during osmotic stress as well as for efficient recovery Phe, Tyr, and Trp have to be produced by de novo synthesis most likely in order to provide sufficient substrates for secondary metabolite production. Our finding that Ser synthesis is also up-regulated during the entire period is in line with a high demand for Ser as a precursor of Trp synthesis. During salt stress, which in general had a less severe effect on amino acid metabolism than PEG treatment, there was no increase in free Phe, Tyr, or Trp indicating that the control steady state levels were sufficient to support secondary metabolite synthesis.

We also observed a significant depletion of free Arg during recovery from low water potential although Arg synthesis was up-regulated. These results indicate that large amounts of Arg might be required for polyamine synthesis and/or an increased production of the gasotransmitter NO particularly during the recovery process. This 
hypothesis is in line with the induction of spermidine synthase involved in polyamine metabolism and nitrate reductase 2 producing NO during stress release (Table S1). Polyamines as well as NO have been implicated in salt and drought tolerance (Alcázar et al., 2006, Alcázar et al., 2010; Domingos, Prado, Wong, Gehring, \& Feijo, 2015; Krasensky \& Jonak, 2012).

\subsection{3 | Amino acid degradation for ATP production and detoxification}

During senescence but also under stress situations restricting photosynthesis, proteins are degraded into free amino acids before they are remobilized to other parts of the plant or used as alternative substrates for mitochondrial ATP production (Araújo et al., 2011; Hildebrandt, 2018; Huang \& Jander, 2017). The in vitro approach used for this study also led to massive stress-induced proteolysis demonstrated by a drop in total protein content after PEG and salt treatment (Figure 2). At the same time, the total content in free amino acids increased. Both effects were more pronounced during PEG than during salt stress. The significant induction of catabolic pathways for the branched-chain amino acids, Lys, and Cys is well in line with their postulated role as an alternative substrate for mitochondrial respiration. The accumulation of these normally low abundant amino acids during PEG treatment is most likely the result of proteolysis because the synthesis pathways were down-regulated. During salt stress, catabolism was obviously fast enough to quantitatively remove surplus amino acids produced by protein degradation because we did not detect significant changes in the content of Val, Leu, Ile, Lys, or Met. A previous study using Arabidopsis plants grown on an artificial substrate also came to the conclusion that drought-induced accumulation of branched-chain amino acids was caused by ABA-regulated protein degradation (Huang \& Jander, 2017), and published transcriptome and metabolome datasets reveal a similar trend for other low abundant amino acids (Hildebrandt, 2018). The functional relevance of branched-chain amino acid and Lys catabolism for drought stress tolerance becomes obvious in mutant lines for different enzymatic steps that show early symptoms of wilting, necrosis, and higher rates of water loss during dehydration (Pires et al., 2016).

Our results indicate that there might be a preference for fast degradation of specific amino acids to return to control levels as soon as possible after stress release. Because amino acid degradation rates correlated with their inhibitory effect on root growth, the need for rapid detoxification might be the reason for this finding. In fact, Lys degradation was strongly induced after PEG stress, and it was also the most toxic amino acid. The high efficiency of Lys catabolism has been demonstrated before in different plant species (Stepansky et al., 2006). Because Lys is an essential amino acid for human nutrition that is present in particularly low levels in crop plants, extensive efforts have been made to increase the Lys content in Arabidopsis and different crops such as rice and maize (Wang, Xu, Wang, \& Galili, 2017). However, this approach was only moderately successful because plants were able to eliminate additional Lys produced by increased synthesis rates very efficiently, whereas an additional block in Lys catabolism led to growth inhibition and an abnormal seed composition (Galili \& Amir, 2013; Karchi, Shaul, \& Galili, 1994; Yang et al.,
2018). Manipulation of Lys metabolism also induces changes in photosynthesis and amino acid metabolism similar to the effect of stress treatments observed here (Cavalcanti et al., 2018). Similar drawbacks have been reported from attempts to increase seed contents of Met, which is also essential for human nutrition (Galili \& Amir, 2013). A possible reason for the need to strictly regulate the concentrations of specific amino acids might be that they act as a signalling molecule, which has been postulated for Leu (Hannah et al., 2010). In addition, some amino acids are precursors for metabolic signals such as Lys producing $\mathrm{N}$-hydroxy pipecoline and a-aminoadipic acid as mediators in pathogen response and Met required for the synthesis of the phytohormone ethylene (Chen et al., 2018; Hartmann et al., 2018; Zeier, 2013). Signals are normally present in low and strictly controlled concentrations, so that a sudden increase will most likely have detrimental effects.

\section{5 | CONCLUSIONS}

Our results provide to our knowledge the first combined metabolomic and proteomic analysis of the regulation of amino acid metabolism during stress release in plants. The data obtained here provide evidence for a rapid regulation of both amino acid levels and enzymes that mediate the developmental switch to cope with stress and the likely resumption of growth following stress release. Our analysis reveals that during stress release plants acclimate their entire metabolism involving a proteomic and metabolic response that has to be tightly regulated. Further, combined analysis of mutant and wild type plants will help to elucidate the detailed mechanism involved in the crucial significance of amino acid metabolism in response to biotic and abiotic stress.

\section{ACKNOWLEDGEMENTS}

We thank Christa Ruppelt for excellent technical assistance in performing the root toxicity tests. This work was supported by the binational science funding programme "PROBRAL" of the Deutsche Akademische Austauschdienst (DAAD; funds provided by the Bundesministerium für Bildung und Forschung-BMBF) and the Coordenação de Aperfeiçoamento de Pessoal de Nível Superior (CAPES), Refs: Project-ID PROBRAL \#423/14. Research fellowships granted by the National Council for Scientific and Technological Development (CNPq-Brazil) to A.N.N. and W.L.A. are gratefully acknowledged.

\section{ORCID}

Wagner L. Araújo (10) https://orcid.org/0000-0002-4796-2616

Hans-Peter Braun (10) https://orcid.org/0000-0002-4459-9727

Tatjana M. Hildebrandt (D) https://orcid.org/0000-0002-3562-5241

\section{REFERENCES}

Abrahám, E., Hourton-Cabassa, C., Erdei, L., \& Szabados, L. (2010). Methods for determination of proline in plants. Methods in Molecular Biology, 639, 317-331. https://doi.org/10.1007/978-1-60761-702-0_20

Aebi, H. (1984). Catalase in vitro. Methods in Enzymology, 105, 121-126. https://doi.org/10.1016/S0076-6879(84)05016-3

Alcázar, R., Altabella, T., Marco, F., Bortolotti, C., Reymond, M., Koncz, C., ... Tiburcio, A. F. (2010). Polyamines: Molecules with regulatory 
functions in plant abiotic stress tolerance. Planta, 231, 1237-1249. https://doi.org/10.1007/s00425-010-1130-0

Alcázar, R., Marco, F., Cuevas, J. C., Patron, M., Ferrando, A., Carrasco, P., ... Altabella, T. (2006). Involvement of polyamines in plant response to abiotic stress. Biotechnology Letters, 28, 1867-1876. https://doi.org/ 10.1007/s10529-006-9179-3

Aleksza, D., Horváth, G. V., Sándor, G., \& Szabados, L. (2017). Proline accumulation is regulated by transcription factors associated with phosphate starvation. Plant Physiology, 175, 555-567. https://doi. org/10.1104/pp.17.00791

Amir, R. (2010). Current understanding of the factors regulating methionine content in vegetative tissues of higher plants. Amino Acids, 39, 917-931. https://doi.org/10.1007/s00726-010-0482-x

Araújo, W. L., Tohge, T., Ishizaki, K., Leaver, C. J., \& Fernie, A. R. (2011). Protein degradation-An alternative respiratory substrate for stressed plants. Trends in Plant Science, 16, 489-498. https://doi.org/10.1016/ j.tplants.2011.05.008

Barnett, N. M., \& Naylor, A. W. (1966). Amino acid and protein metabolism in Bermuda grass during water stress. Plant Physiology, 41, 1222-1230. https://doi.org/10.1104/pp.41.7.1222

Barros, J. A. S., Cavalcanti, J. H. F., Medeiros, D. B., Nunes-Nesi, A., AvinWittenberg, T., Fernie, A. R., \& Araújo, W. L. (2017). Autophagy deficiency compromises alternative pathways of respiration following energy deprivation in Arabidopsis thaliana. Plant Physiology, 175, 62-76. https://doi.org/10.1104/pp.16.01576

Bhaskara, G. B., Yang, T.-H., \& Verslues, P. E. (2015). Dynamic proline metabolism: Importance and regulation in water limited environments. Frontiers in Plant Science, 6, 484.

Bradford, M. M. (1976). A rapid and sensitive method for the quantitation of microgram quantities of protein utilizing the principle of protein-dye binding. Analytical Biochemistry, 72, 248-254. https://doi.org/ 10.1016/0003-2697(76)90527-3

Cavalcanti, J. H. F., Kirma, M., Barros, J. A. S., Quinhones, C. G. S., PereiraLima, Í. A., Obata, T., ... Araújo, W. L. (2018). An LL-diaminopimelate aminotransferase mutation leads to metabolic shifts and growth inhibition in Arabidopsis. Journal of Experimental Botany, 69, 5489-5506. https://doi.org/10.1093/jxb/ery325

Cebollero, E., Reggiori, F., \& Kraft, C. (2012). Reticulophagy and ribophagy: Regulated degradation of protein production factories. International Journal of Cell Biology, 2012, 182834.

Chaves, M. M. (1991). Effects of water deficits on carbon assimilation. Journal of Experimental Botany, 42, 1-16. https://doi.org/10.1093/ $\mathrm{jxb} / 42.1 .1$

Chaves, M. M., Flexas, J., \& Pinheiro, C. (2009). Photosynthesis under drought and salt stress: Regulation mechanisms from whole plant to cell. Annals of Botany, 103, 551-560. https://doi.org/10.1093/aob/ mcn125

Chen, Y.-C., Holmes, E. C., Rajniak, J., Kim, J.-G., Tang, S., Fischer, C. R., ... Sattely, E. S. (2018). N-hydroxy-pipecolic acid is a mobile metabolite that induces systemic disease resistance in Arabidopsis. Proceedings of the National Academy of Sciences of the United States of America, 115, E4920-E4929. https://doi.org/10.1073/pnas.1805291115

Cox, J., \& Mann, M. (2008). MaxQuant enables high peptide identification rates, individualized p.p.b.-range mass accuracies and proteome-wide protein quantification. Nature Biotechnology, 26, 1367-1372. https:// doi.org/10.1038/nbt.1511

Cross, J. M., von Korff, M., Altmann, T., Bartzetko, L., Sulpice, R., Gibon, Y., ... Stitt, M. (2006). Variation of enzyme activities and metabolite levels in 24 Arabidopsis accessions growing in carbon-limited conditions. Plant Physiology, 142, 1574-1588. https://doi.org/10.1104/ pp.106.086629

Cruz, C. D. (2013). GENES-A software package for analysis in experimental statistics and quantitative genetics. Acta Scientiarum Agronomy, 35, 271-276.

Deuschle, K., Funck, D., Forlani, G., Stransky, H., Biehl, A., Leister, D., ... Frommer, W. B. (2004). The role of $\Delta^{1}$-pyrroline-5-carboxylate dehydrogenase in proline degradation. The Plant Cell, 16, 3413-3425. https://doi.org/10.1105/tpc.104.023622

Deuschle, K., Funck, D., Hellmann, H., Däschner, K., Binder, S., \& Frommer, W. B. (2001). A nuclear gene encoding mitochondrial $\Delta^{1}$-pyrroline-5carboxylate dehydrogenase and its potential role in protection from proline toxicity. The Plant Journal, 27, 345-356. https://doi.org/ 10.1046/j.1365-313X.2001.01101.x

Domingos, P., Prado, A. M., Wong, A., Gehring, C., \& Feijo, J. A. (2015). Nitric oxide: A multitasked signaling gas in plants. Molecular Plant, 8, 506-520. https://doi.org/10.1016/j.molp.2014.12.010

Draper, S. R. (1972). Amino acid changes associated with low temperature treatment of Lolium perenne. Phytochemistry, 11, 639-641. https://doi. org/10.1016/0031-9422(72)80025-6

Ferreira Júnior, D. C., Gaion, L. A., Sousa Júnior, G. S., Santos, D. M. M., \& Carvalho, R. F. (2018). Drought-induced proline synthesis depends on root-to-shoot communication mediated by light perception. Acta Physiologiae Plantarum, 40, 363.

Floyd, B. E., Morriss, S. C., Macintosh, G. C., \& Bassham, D. C. (2012). What to eat: Evidence for selective autophagy in plants. Journal of Integrative Plant Biology, 54, 907-920. https://doi.org/10.1111/j.17447909.2012.01178.x

Fougère, F., Le Rudulier, D., \& Streeter, J. G. (1991). Effects of salt stress on amino acid, organic acid, and carbohydrate composition of roots, bacteroids, and cytosol of alfalfa (Medicago sativa L.). Plant Physiology, 96, 1228-1236. https://doi.org/10.1104/pp.96.4.1228

Frolov, A., Bilova, T., Paudel, G., Berger, R., Balcke, G. U., Birkemeyer, C., \& Wessjohann, L. A. (2017). Early responses of mature Arabidopsis thaliana plants to reduced water potential in the agar-based polyethylene glycol infusion drought model. Journal of Plant Physiology, 208, 70-83. https://doi.org/10.1016/j.jplph.2016.09.013

Fromm, S., Göing, J., Lorenz, C., Peterhänsel, C., \& Braun, H.-P. (2016). Depletion of the "gamma-type carbonic anhydrase-like" subunits of complex I affects central mitochondrial metabolism in Arabidopsis thaliana. Biochimica et Biophysica Acta, 1857, 60-71. https://doi.org/ 10.1016/j.bbabio.2015.10.006

Fürst, P., Pollack, L., Graser, T. A., Godel, H., \& Stehle, P. (1990). Appraisal of four pre-column derivatization methods for the high-performance liquid chromatographic determination of free amino acids in biological materials. Journal of Chromatography A, 499, 557-569. https://doi. org/10.1016/S0021-9673(00)97000-6

Galili, G., \& Amir, R. (2013). Fortifying plants with the essential amino acids lysine and methionine to improve nutritional quality. Plant Biotechnology Journal, 11, 211-222. https://doi.org/10.1111/pbi.12025

Gharibi, S., Tabatabaei, B. E. S., Saeidi, G., \& Goli, S. A. H. (2016). Effect of drought stress on total phenolic, lipid peroxidation, and antioxidant activity of Achillea species. Applied Biochemistry and Biotechnology, 178, 796-809. https://doi.org/10.1007/s12010-015-1909-3

Giannopolitis, C. N., \& Ries, S. K. (1977). Superoxide dismutases: I. Occurrence in higher plants. Plant Physiology, 59, 309-314. https://doi.org/ 10.1104/pp.59.2.309

Hannah, M. A., Caldana, C., Steinhauser, D., Balbo, I., Fernie, A. R., \& Willmitzer, L. (2010). Combined transcript and metabolite profiling of Arabidopsis grown under widely variant growth conditions facilitates the identification of novel metabolite-mediated regulation of gene expression. Plant Physiology, 152, 2120-2129. https://doi.org/ 10.1104/pp.109.147306

Hartmann, M., Zeier, T., Bernsdorff, F., Reichel-Deland, V., Kim, D., Hohmann, M., ... Zeier, J. (2018). Flavin monooxygenase-generated $\mathrm{N}$-hydroxypipecolic acid is a critical element of plant systemic immunity. Cell, 173, 456-469.e16. https://doi.org/10.1016/j. cell.2018.02.049

Hildebrandt, T. M. (2018). Synthesis versus degradation: Directions of amino acid metabolism during Arabidopsis abiotic stress response. Plant Molecular Biology, 98, 121-135. https://doi.org/10.1007/ s11103-018-0767-0 
Hildebrandt, T. M., Nunes Nesi, A., Araújo, W. L., \& Braun, H.-P. (2015) Amino acid catabolism in plants. Molecular Plant, 8, 1563-1579. https://doi.org/10.1016/j.molp.2015.09.005

Hirota, T., Izumi, M., Wada, S., Makino, A., \& Ishida, H. (2018). Vacuolar protein degradation via autophagy provides substrates to amino acid catabolic pathways as an adaptive response to sugar starvation in Arabidopsis thaliana. Plant and Cell Physiology, 59, 1363-1376. https://doi.org/10.1093/pcp/pcy005

Huang, T., \& Jander, G. (2017). Abscisic acid-regulated protein degradation causes osmotic stress-induced accumulation of branched-chain amino acids in Arabidopsis thaliana. Planta, 246, 737-747. https://doi.org/ 10.1007/s00425-017-2727-3

Karchi, H., Shaul, O., \& Galili, G. (1994). Lysine synthesis and catabolism are coordinately regulated during tobacco seed development. Proceedings of the National Academy of Sciences of the United States of America, 91, 2577-2581. https://doi.org/10.1073/pnas.91.7.2577

Kraft, C., Deplazes, A., Sohrmann, M., \& Peter, M. (2008). Mature ribosomes are selectively degraded upon starvation by an autophagy pathway requiring the Ubp3p/Bre5p ubiquitin protease. Nature Cell Biology, 10, 602-610. https://doi.org/10.1038/ncb1723

Krasensky, J., \& Jonak, C. (2012). Drought, salt, and temperature stressinduced metabolic rearrangements and regulatory networks. Journal of Experimental Botany, 63, 1593-1608. https://doi.org/10.1093/jxb/ err460

Liang, X., Zhang, L., Natarajan, S. K., \& Becker, D. F. (2013). Proline mechanisms of stress survival. Antioxidants and Redox Signaling, 19, 998-1011. https://doi.org/10.1089/ars.2012.5074

Lugan, R., Niogret, M.-F., Leport, L., Guégan, J.-P., Larher, F. R., Savouré, A., ... Bouchereau, A. (2010). Metabolome and water homeostasis analysis of Thellungiella salsuginea suggests that dehydration tolerance is a key response to osmotic stress in this halophyte. The Plant Journal, 64, 215-229. https://doi.org/10.1111/j.1365-313X.2010.04323.x

Madhava Rao, K. V., Janardhan Reddy, K., \& Raghavendra, A. S. (Eds.) (2006). Physiology and molecular biology of stress tolerance in plants. Dordrecht: Springer.

Mahajan, S., \& Tuteja, N. (2005). Cold, salinity and drought stresses: An overview. Archives of Biochemistry and Biophysics, 444, 139-158. https://doi.org/10.1016/j.abb.2005.10.018

Martinelli, T., Whittaker, A., Bochicchio, A., Vazzana, C., Suzuki, A., \& Masclaux-Daubresse, C. (2007). Amino acid pattern and glutamate metabolism during dehydration stress in the 'resurrection' plant Sporobolus stapfianus: A comparison between desiccation-sensitive and desiccation-tolerant leaves. Journal of Experimental Botany, 58, 3037-3046. https://doi.org/10.1093/jxb/erm161

Munns, R., James, R. A., \& Läuchli, A. (2006). Approaches to increasing the salt tolerance of wheat and other cereals. Journal of Experimental Botany, 57, 1025-1043. https://doi.org/10.1093/jxb/erj100

Murashige, T., \& Skoog, F. (1962). A revised medium for rapid growth and bio assays with tobacco tissue cultures. Physiologia Plantarum, 15 473-497. https://doi.org/10.1111/j.1399-3054.1962.tb08052.x

Nakano, Y., \& Asada, K. (1981). Hydrogen peroxide is scavenged by ascorbate-specific peroxidase in spinach chloroplasts. Plant and Cell Physiology, 22, 867-880.

Peng, Z., Lu, Q., \& Verma, D. P. S. (1996). Reciprocal regulation of $\Delta^{1}$ pyrroline-5-carboxylate synthetase and proline dehydrogenase genes controls proline levels during and after osmotic stress in plants. Molecular Genetics and Genomics, 253, 334-341.

Perez-Alfocea, F., Estan, M. T., Caro, M., \& Guerrier, G. (1993). Osmotic adjustment in Lycopersicon esculentum and L. pennellii under $\mathrm{NaCl}$ and polyethylene glycol 6000 iso-osmotic stresses. Physiologia Plantarum, 87, 493-498. https://doi.org/10.1111/j.1399-3054.1993.tb02498.x

Pires, M. V., Pereira Júnior, A. A., Medeiros, D. B., Daloso, D. M., Pham, P. A., Barros, K. A., ... Fernie, A. R. (2016). The influence of alternative pathways of respiration that utilize branched-chain amino acids following water shortage in Arabidopsis. Plant, Cell and Environment, 39, 1304-1319. https://doi.org/10.1111/pce.12682
Porra, R. J., Thompson, W. A., \& Kriedemann, P. E. (1989). Determination of accurate extinction coefficients and simultaneous equations for assaying chlorophylls $a$ and $b$ extracted with four different solvents: Verification of the concentration of chlorophyll standards by atomic absorption spectroscopy. Biochimica et Biophysica Acta, 975 , 384-394. https://doi.org/10.1016/S0005-2728(89)80347-0

Ranieri, A., Bernardi, R., Lanese, P., \& Soldatini, G. F. (1989). Changes in free amino acid content and protein pattern of maize seedlings under water stress. Environmental and Experimental Botany, 29, 351-357. https://doi.org/10.1016/0098-8472(89)90009-9

Ren, Y., Miao, M., Meng, Y., Cao, J., Fan, T., Yue, J., ... Cao, S. (2018). DFR1mediated inhibition of proline degradation pathway regulates drought and freezing tolerance in Arabidopsis. Cell Reports, 23, 3960-3974. https://doi.org/10.1016/j.celrep.2018.04.011

Schaedle, M., \& Bassham, J. A. (1977). Chloroplast glutathione reductase. Plant Physiology, 59, 1011-1012. https://doi.org/10.1104/ pp.59.5.1011

Schertl, P., \& Braun, H.-P. (2014). Respiratory electron transfer pathways in plant mitochondria. Frontiers in Plant Science, 5, 163.

Schlesier, B., Bréton, F., \& Mock, H.-P. (2003). A hydroponic culture system for growing Arabidopsis thaliana plantlets under sterile conditions. Plant Molecular Biology Reporter, 21, 449-456. https://doi.org/10.1007/ BF02772594

Sharma, S., \& Verslues, P. E. (2010). Mechanisms independent of abscisic acid (ABA) or proline feedback have a predominant role in transcriptional regulation of proline mechanism during low water potential and stress recovery. Plant, Cell and Evironment, 33, 1838-1851. https:// doi.org/10.1111/j.1365-3040.2010.02188.x

Shinde, S., Villamor, J. G., Lin, W., Sharma, S., \& Verslues, P. E. (2016). Proline coordination with fatty acid synthesis and redox metabolism of chloroplast and mitochondria. Plant Physiology, 172, 1074-1088. https://doi.org/10.1104/pp.16.01097

Showler, A. T. (2002). Effects of water deficit stress, shade, weed competition, and kaolin particle film on selected foliar free amino acid accumulations in cotton, Gossypium hirsutum (L.). Journal of Chemical Ecology, 28, 631-651. https://doi.org/10.1023/A:1014556515489

Stepansky, A., Less, H., Angelovici, R., Aharon, R., Zhu, X., \& Galili, G. (2006). Lysine catabolism, an effective versatile regulator of lysine level in plants. Amino Acids, 30, 121-125. https://doi.org/10.1007/s00726005-0246-1

Szabados, L., \& Savouré, A. (2010). Proline: A multifunctional amino acid. Trends in Plant Science, 15, 89-97. https://doi.org/10.1016/j. tplants.2009.11.009

Thal, B., Braun, H.-P., \& Eubel, H. (2018). Proteomic analysis dissects the impact of nodulation and biological nitrogen fixation on Vicia faba root nodule physiology. Plant Molecular Biology, 97, 233-251. https://doi. org/10.1007/s11103-018-0736-7

Thimm, O., Bläsing, O., Gibon, Y., Nagel, A., Meyer, S., Krüger, P., ... Stitt, M. (2004). MAPMAN: A user-driven tool to display genomics data sets onto diagrams of metabolic pathways and other biological processes. The Plant Journal, 37, 914-939. https://doi.org/10.1111/j.1365313X.2004.02016.X

Tyanova, S., Temu, T., Sinitcyn, P., Carlson, A., Hein, M. Y., Geiger, T., ... Cox, J. (2016). The Perseus computational platform for comprehensive analysis of (prote)omics data. Nature Methods, 13, 731-740. https:// doi.org/10.1038/nmeth.3901

Tzin, V., \& Galili, G. (2010). New insights into the shikimate and aromatic amino acids biosynthesis pathways in plants. Molecular Plant, 3, 956-972. https://doi.org/10.1093/mp/ssq048

van der Weele, C. M., Spollen, W. G., Sharp, R. E., \& Baskin, T. I. (2000). Growth of Arabidopsis thaliana seedlings under water deficit studied by control of water potential in nutrient-agar media. Journal of Experimental Botany, 51, 1555-1562. https://doi.org/10.1093/jexbot/ 51.350.1555

Verslues, P. E., Agarwal, M., Katiyar-Agarwal, S., Zhu, J., \& Zhu, J.-K. (2006). Methods and concepts in quantifying resistance to drought, salt and 
freezing, abiotic stresses that affect plant water status. The Plant Journal, 45, 523-539. https://doi.org/10.1111/j.1365-313X.2005.02593.x

Verslues, P. E., \& Sharma, S. (2010). Proline metabolism and its implications for plant-environment interaction. Arabidopsis Book, 8, e0140. https:// doi.org/10.1199/tab.0140

Wang, G., Xu, M., Wang, W., \& Galili, G. (2017). Fortifying horticultural crops with essential amino acids: A review. International Journal of Molecular Sciences, 18, 1306. https://doi.org/10.3390/ijms18061306

Yang, Q.-Q., Zhao, D.-S., Zhang, C.-Q., Wu, H.-Y., Li, Q.-F., Gu, M.-H., ... Liu, Q.-Q. (2018). A connection between lysine and serotonin metabolism in rice endosperm. Plant Physiology, 176, 1965-1980. https://doi. org/10.1104/pp.17.01283

Zeier, J. (2013). New insights into the regulation of plant immunity by amino acid metabolic pathways. Plant, Cell and Environment, 36, 2085-2103. https://doi.org/10.1111/pce.12122

\section{SUPPORTING INFORMATION}

Additional supporting information may be found online in the Supporting Information section at the end of the article.

Figure S1. Principal component analysis of stress parameters.

Figure $\mathrm{S} 2$. In situ detection of $\mathrm{H}_{2} \mathrm{O}_{2}$ by DAB staining and $\mathrm{O}_{2}{ }^{-}$by NBT staining.
Figure S3. Scheme of all currently known reaction steps involved in amino acid synthesis and degradation pathways as well as of the enzymes catalyzing committed steps leading to the synthesis of amino acid derived secondary metabolites.

Table S1. Shotgun proteomics dataset of shoots harvested before stress treatment, after $24 \mathrm{~h}$ of control, $\mathrm{NaCl}$ (150 mM) or PEG (291 g $\mathrm{L}^{-1}$ ) stress, and after $6 \mathrm{~h}$ and $18 \mathrm{~h}$ of recovery.

Table S2. Amino acid contents in control samples of Arabidopsis seedlings.

Table S3. Amino acids profile of Arabidopsis seedlings during stress and recovery.

Table S4. Complete list of Arabidopsis enzymes involved in amino acid metabolism including the shotgun-MS dataset.

How to cite this article: Batista-Silva W, Heinemann B, Rugen $\mathrm{N}$, et al. The role of amino acid metabolism during abiotic stress release. Plant Cell Environ. 2019;1-15. https://doi. org/10.1111/pce.13518 